as a combination of pelorus and station pointer. From your alter-course position for the first leg, draw a fine line to the edge of the next salient point or lighthouse in sight ahead. Measure the enclosed angle quickly with parallel rules and compass rose and instruct your officer, stationed by the standard compass, to alter course until this salient point or light or other object bears the required number of degrees on the appropriate bow. If you do this quickly enough and the vessel alters course with full helm to start with, your ship's head by lubberline over the standard compass must be on the proper course. A quick comparison with the true course as laid down on the chart will give you the present compass error, though this may change as the vessel settles on the new course; careful conning and the use of all your instruments including vertical sextant angles of known heights around should take care of such errors as changing compass deviation and current set, windage, \&c. Also when once enclosed a quick glance astern will often give you some object to turn directly away from and will be useful in detecting drift.

This method of comparative bearings corrects itself each leg and errors are not accumulative. Therefore it can be used again and again with complete confidence.

It will be easily seen that this method can also be applied directly to radar navigation when working through in thick weather by applying these principles directly to the viewer.

\title{
Navigation in the Days of Sail
}

$$
\text { from Captain A. R. Perry Shaw }
$$

Ar the turn of the century I served in two four-masted barques under three captains hailing respectively from Nova Scotia, Liverpool and Glasgow. All three were rather elderly and their practice of navigation did not exhaust the theory even then included in the syllabus for second mate. However, it may be interesting to recall their methods.

The captains personally had to supply, in addition to sextants and nautical tables, chronometers, charts, 'Pilots', patent logs and nautical almanacs. I doubt if they bothered about tide tables. These were all kept in the captains' bedrooms. Each of these captains rented and insured two chronometers. In port, if convenient, these went ashore to a chronometer dealer and just before sailing were brought on board, each with a card showing its maker's name and number with error of instrument and its daily rate. If at sea it was possible to get a longitude by bearings of the land and also longitude by sights, they would be checked and error and rate corrected. Of course in sail it was impossible to maintain an even temperature in the chronometer compartment. It was generally assumed that, owing to effect of change of temperature on the lubricating oil, a chronometer ran slower in cold weather and faster in hot. I don't know when they were cleaned. Perhaps if a ship did return to where the chronometers' owner had his place of business they might be cleaned before being issued to some other ship.

For financial reasons charts were few, generally covering large areas. 'Blue backs' were the favourites. I don't know if newest editions always replaced 
older ones on board. The captain could see the Notices to Mariners at Consulates but I doubt if sufficient stocks were available to issue five or six back monthly numbers to each captain in port. Consequently each captain would note down any changes affecting his next passage only. So charts and Pilots would not be properly up-to-date, not to mention changes happening on the passage. We once went to Delagoa Bay and the captain went well to the north as apparently that was where his chart showed the pilots cruised. After a few hours a steamer passed and, in answer to our signals, told us to go much farther south where we picked up the pilot.

One of these captains towed a patent log only near his destination. Ordinarily the log was hove every two hours. The others constantly towed a log. One had two cherubs and the other had two of these and a harpoon log.

Ordinarily with favourable conditions a compass error was obtained by morning amplitude. Then at $8 \mathrm{a} . \mathrm{m}$. the captain and mate would take sights and a bearing and work out both longitude and azimuth by logarithms. At noon latitude would be obtained. On Sundays the second mate also might be allowed to take the noon altitude. If unable to get sights at $8 \mathrm{a} . \mathrm{m}$. none would be taken later. And of course no correction for latitude was made Bringing Up the longitude for the noon position. Noon was a big event and one of the boys stood by to make eight bells and to set the clock at 12 . If there was no noon observation the clock was usually not corrected. No p.m. sights, no evening amplitude and no star sights were taken.

Dead reckoning was carefully kept on a properly ruled slate, kept in the mate's room and entered every four hours with all necessary details. It would be carefully worked up by captain and mate for the 8 a.m. sights and again for the noon position.

On one voyage one of these captains proudly showed us a new purchase he made in the last port-the latest edition of Norie's with A.B.C. tables and he explained their use for a time azimuth. But he had no idea they would be used for a position line or for correcting longitude for error in assumed latitude.

Soundings were made by hand lead and deep-sea lead. But one captain had a mechanism he used to attach above the deep-sea lead. I don't remember the maker's name but vanes revolved and a dial recorded as it descended but locked when ascending. It was a useful check on the line measurement as it was impossible to hold the ship stationary while the cast was made. I don't remember the hand lead ever being used, though the boys used to practise at times in port. The deepsea lead was hove on very few occasions.

Ships had become large and slow, yet they made quite reasonable passages and excellent landfalls. So in spite of the simplicity of their navigation, I consider that these three captains were not only good seamen but fine navigators. 